\title{
An alternative method of endoscopic retrieval of a proximally migrated biliary plastic stent using a "sphincterotome hooking the stent" technique
}

Stent migration occurs in about $5 \%-10 \%$ of patients undergoing biliary stenting. The risk of proximal stent migration is higher with benign biliary strictures, stenosis of the lower bile duct, bile duct diameter $>10 \mathrm{~mm}$, duration of stent placement $>1$ month, and the use of straight and 10-Fr stents [1]. Devices that have been used for the endoscopic removal of stents are biopsy forceps, grasping forceps, basket catheters, balloon catheters, snares, ultra slim cholangioscopes, and the Soehendra stent retriever [2-4]. We present the case of a 38-year-old woman who was treated with sphincterotomy and insertion of a 6-cm, 10-Fr, straight, plastic, biliary stent for a postcholecystectomy bile duct leakage. Gastroduodenoscopy 30 days later revealed that the stent was not "in situ," and removal of the proximally migrated stent was attempted.

Initially, a guidewire was advanced through the lumen of the stent ( $\bullet$ Fig. 1 ) and then a stone retrieval balloon was used, over the wire, to remove the stent. However, this was unsuccessful because the tip of the balloon catheter could not advance past the proximal end of the stent. A sphincterotome was then used, which was advanced successfully over the wire, to $2-3 \mathrm{~cm}$ beyond the proximal end of the stent, probably because of its stiffness compared with the balloon. Then, the proximal end of the sphincterotome was bent to form a "hook" on which to catch the stent ( $\bullet$ Fig. 2), and the sphincterotome was pulled back slowly. When the hooked stent appeared through the papilla ( Fig.3), the endoscope was pulled back in the stomach, from where the stent was finally retrieved using a grasping forceps ( Video 1 ).

We propose the use of this previously unreported, simple, and technically easy method for the endoscopic retrieval of a proximally migrated biliary stent.

Endoscopy_UCTN_Code_CPL_1AK_2AD

Competing interests: None

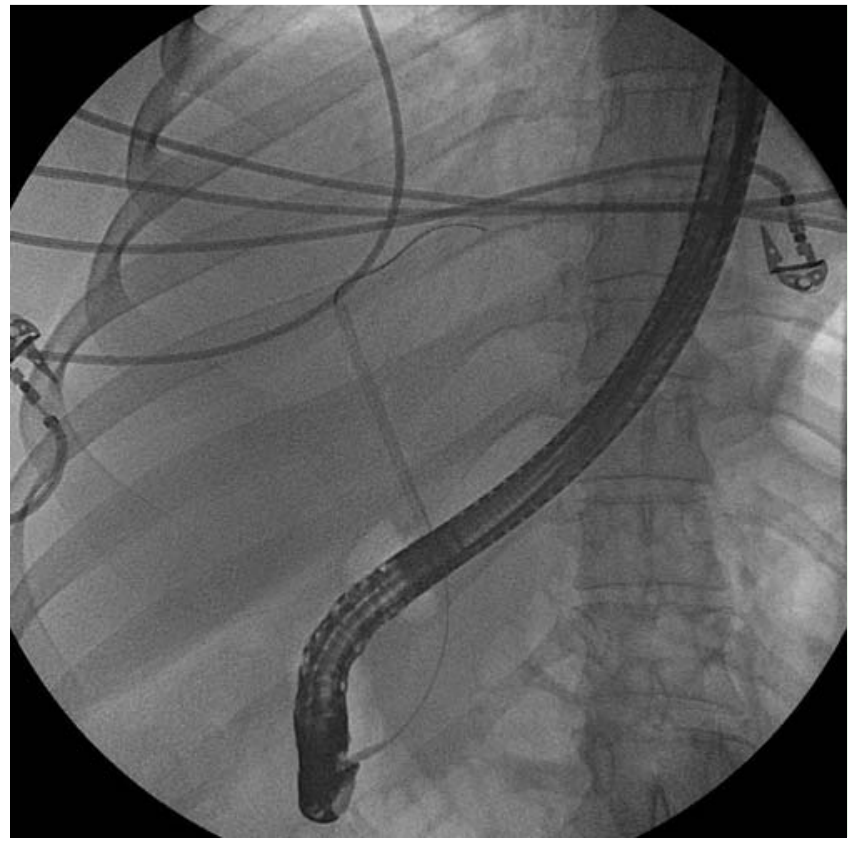

Fig. 1 Radiological image showing a guidewire being advanced through the lumen of the stent.

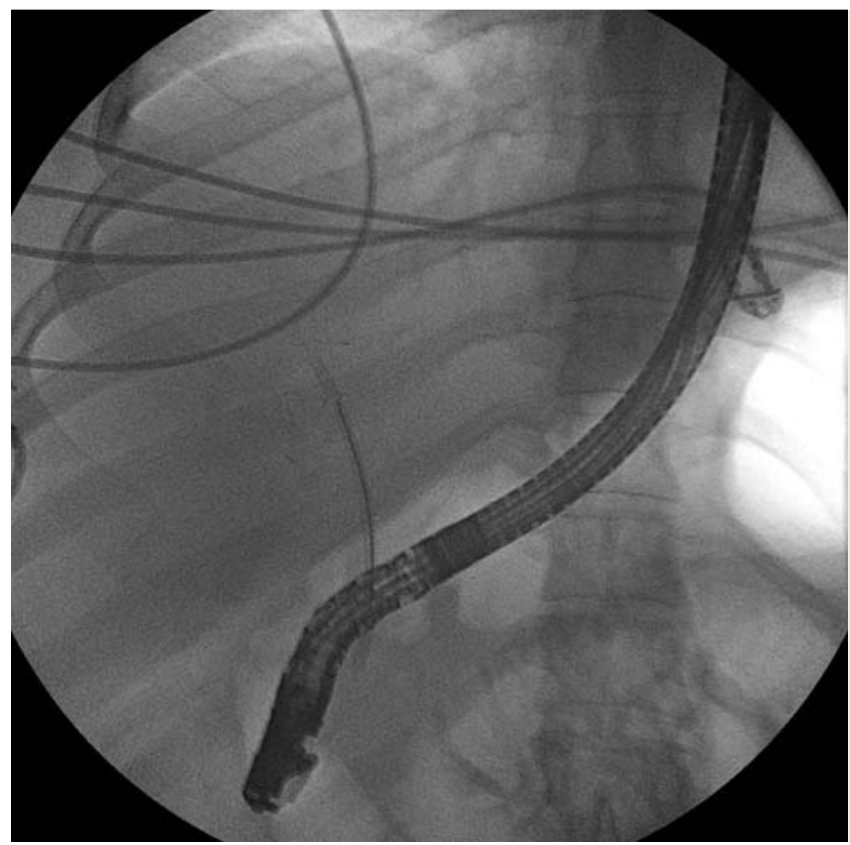

Fig. 2 Radiological image showing the sphincterotome, which was advanced through the stent and then bent in order to "hook" the stent.

\section{Video 1}

Endoscopic retrieval of a proximally migrated, plastic, biliary stent. 

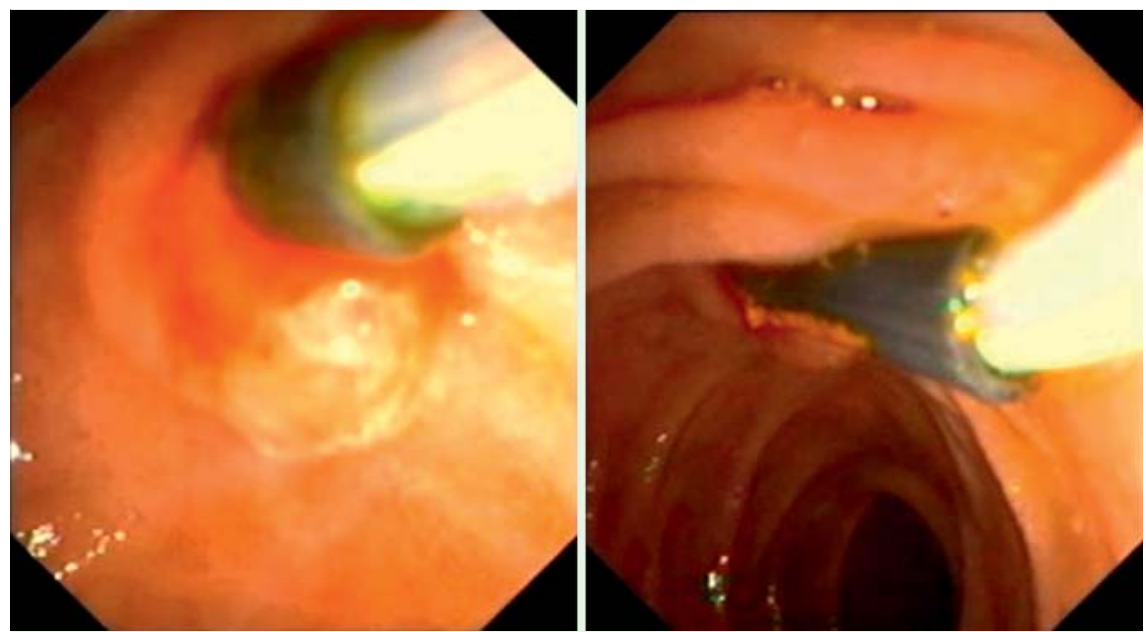

Bibliography

DOI http://dx.doi.org/

10.1055/s-0034-1391242

Endoscopy 2015; 47: E64-E65

(c) Georg Thieme Verlag KG

Stuttgart · New York

ISSN 0013-726X

Corresponding author Nikolaos Kyriakos, MD, PhD

Gastroenterology Department 401 Army General Hospital

N.Vitali 38

Cholargos

Athens 15562

Greece

Fax: +30-210-7494095

nikos_kiriakos@yahoo.gr

Fig.3 Endoscopic image showing sphincterotome and "hooked" stent appearing through the papilla.

\section{Christos Liatsos ${ }^{1}$, Nikolaos Kyriakos ${ }^{1}$, Grigorios Anthopoulos ${ }^{1}$, Michalis Galanopoulos' ${ }^{1}$, Evangelos Kalafatis ${ }^{1}$, Christos Mavrogiannis ${ }^{2}$}

${ }^{1}$ Gastroenterology Department, 401 Army General Hospital of Athens, Athens,

Greece

${ }^{2}$ Academic Department of Gastroenterology, Faculty of Nursing, Kifissia General and Oncology Hospital, Athens University, Athens, Greece

\section{References}

1 Kawaguchi Y, Ogawa M, Kawashima Y et al. Risk factors for proximal migration of biliary tube stents. World J Gastroenterol 2014; 20: $1318-1324$

2 Katsinelos P, Kountouras J, Paroutoglou G et al. Migration of plastic biliary stents and endoscopic retrieval: an experience of three referral centers. Surg Laparosc Endosc Percutan Tech 2009; 19: 217-221

3 Tarnasky PR, Cotton PB, Baillie J et al. Proximal migration of biliary stents: attempted endoscopic retrieval in forty-one patients. Gastrointest Endosc 1995; 42: 513-520

4 Arhan M, Odemiş B, Parlak E et al. Migration of biliary plastic stents: experience of a tertiary center. Surg Endosc 2009; 23: 769 775 